\title{
Industrialización del Camote
}

\begin{abstract}
RESUMEN En el presente trabajo se utilizaron los tres colores de camote que se encontraban en el mercado Grau. El proceso de secado se realizó por tres medios: secado al medio ambiente, la muflay el secador solar de la Escuela de Física.
\end{abstract}

\author{
El objetivo fue obtener harina de Camote con Ia \\ finalidad de remplazar la harina de trigo, para \\ producir fideo, porque el costo es menor y, además, se \\ puede producir camote en los campos desértico con \\ mayor rendimiento.
}

\begin{abstract}
In this study, we used the three colors of sweet potato that was in the market Grau, the drying process was carried out by three means; drying environment, the flask and the solar dryer school physics
\end{abstract}

This work has been developed for sweet potato flour, in order to replace wheat flour to produce noodles, because the cost is lower and also can produce sweetpotato in desert areas with high throughput.
INTRODUCCIÓN. Los bosques dejarán de asegurar el sustento de millones de personas que de ellos dependen para ser sustituidos por papa, camote, aceitera $\mathrm{u}$ otros cultivos energéticos. El agua no se contamine (por el uso de abonos orgánicos) la fauna local no se verá gravemente afectada por enormes desiertos verdes que nos le proporcionarán alimentos, la flora nativa será eliminada y sustituida por extensos monocultivos, y muchas especies locales no serán contaminadas por los organismos genéticamente modificados utilizados en dichos monocultivos, en tanto que los suelos se degradarán por el monocultivo y el uso de agroquímicos. Resulta, por tanto, evidente que esta es una buena solución para la gente, para el ambiente. Sin embargo, es una excelente oportunidad de negocios para grandes empresas que operan a nivel nacional y en particular para las grandes transnacionales. Entre ellas se cuentan las vinculadas a la producción y comercialización de productos agrícolas de exportación; las industrias biotecnológicas y químicas (que aumentarán sus ventas de material transgénico e insumos agrícolas), la industria automotriz (que podrá seguir creciendo bajo un manto "verde"), las nuevas empresas surgidas en la ola de los biocombustibles y las propias empresas petroleras, que ya se están incorporando a este nuevo y lucrativo negocio. Es por ello que tantos gobiernos, organismos de asistencia, agencias bilaterales, organismos multilaterales y expertos internacionales están involucrados en la promoción de esta absurda solución: servir los intereses de esos poderosos grupos económicos; que son quienes dictan las políticas globales en su propio beneficio.

Cabe aclarar, finalmente, que el camote es la solución en el problema de la pobreza. Es más, dentro de un enfoque social y ambientalmente adecuado puede servir para satisfacer parte de las necesidades energéticas de nuestros paises y en particular de las comunidades locales. El problema central es el modelo en el que se le pretende implementar, caracterizado por la gran escala, el monocultivo, el uso masivo de insumos externos, la utilización de transgénicos, la mecanización y su exportación para alimentar el consumo desmedido de energia que se realiza en el Sur en extensiones decorticas y en la selva. En el presente trabajo se ha querido obtener harina de camote para la producción del fideo a nivel artesanal, lo cual ha sido posible porque contenía $65 \%$ de agua

\section{MATERIALES Y MÉTODOS}

\section{Materia Prima y Equipos}

Materia Prima

El camote como materia prima. Se compró en el Mercado Grau a la venta y son de color blanco, de $1,130 \mathrm{~kg}$. Morado de $1,140 \mathrm{~kg}$ y amarrillo de $0,970 \mathrm{~kg}$, los cuales pesaban con cáscara y tierras de acuerdo con lo indicado anteriormente.

Paso siguiente: realizamos el lavado y descascarado para luego partirlos en tamaños pequeñas con la finalidad desecar en menos tiempo.

\section{Secado de la Materia Prima}

\section{Secado al medio ambiente}

Para realizar este tipo de secado se utilizaron los ambientes del Laboratorio de Fisicoquímica y se colocaron sobre papel periódico durante 48 horas que ha sido el tiempo óptimo. 


\section{Secado en el equipo de mufla}

Para realizar este tipo de secado se utilizó el equipo, que se encuentra en el laboratorio de Fisicoquímica a la temperatura de $32{ }^{\circ} \mathrm{C}$ durante 48 horas. Por resultado que se obtuvo no es recomendable para el proceso.

\section{Secador solar}

Para realizar este tipo de secado se utilizó el secador solar de la Facultad de Ciencias que conduce la Escuela de Física, que consta de dos compartimento que están estructurados para realizar cualquier producto, pero los resultados obtenidos no son lo más òptimo esperado por que el tiempo utilizado ha sido de 48 horas, como variaba a la temperatura de $25 \mathrm{a} 35^{\circ} \mathrm{C}$.

\section{RESULTADOS}

\section{Secado de Materia Prima}

Cuadro $\mathrm{N}^{\circ} 01$ Cuadrode Resultados del Secado del Camote

\begin{tabular}{|ll|l|l|lc|}
\hline CLLOR & Peso totalkg & Pesohímedo $\mathrm{kg}$ & \% Hmedad & Peso seco $\mathrm{kg}$ & $\%$ seco \\
\hline MORADO & 1,140 & 0,739 & 65,0 & 0,401 & 35 \\
\hline BLANC0 & 1.030 & 0,660 & 64,1 & 0,370 & 35.9 \\
\hline AMARRLLO & 0,970 & 0,632 & 65,2 & 0,238 & 34,8 \\
\hline
\end{tabular}

Fuente Elaboración Propia

\section{Mollienda}

La mollineada se realizó utilizando un molino de granos, porque en nuestros laboratorios de Fisicoquímica de la Facultad no se cuenta con un molino de granos finos.

\section{Harina Fina}

Para lograr la harina fina se utilizó un colador de cocina la más fina, porque se necesita una harina más fina para le elaboración del fideo.

\section{Elaboración de Fideo}

Para realizar el experimento de producción de fideo se utilizaron los siguientes productos ingredientes : Harina de camote : $0,160 \mathrm{~kg}$

Levadura : $4 \mathrm{~g}$

Agua : $25 \mathrm{ml}$

Sal $: 10 \mathrm{~g}$

Diagrama de Flujo de Proceso de Elaboracion del Fideo

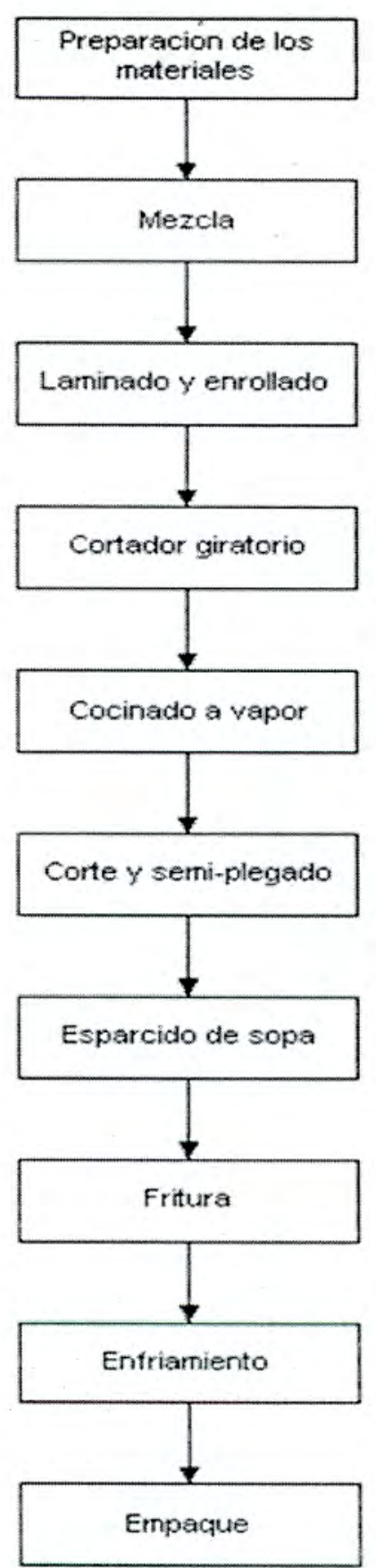




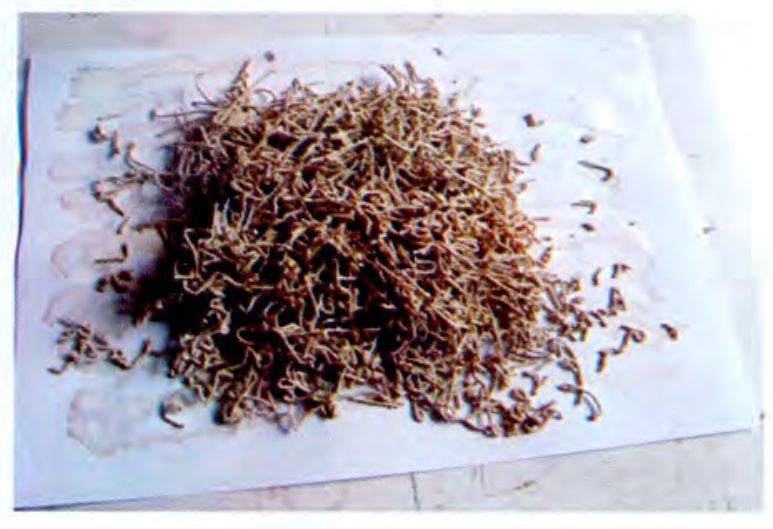

\section{DISCUSIÓN}

Se realizó un análisis cualitativo del producto final, que es de buena calidad, que es posible sustituir en parte la harina de trigo en la producción de fideo, y también en la elaboración del pan.

Para mejorar la producción de fideo se tiene que mejora la molienda más fina, para mejorar la calidad del producto final.

\section{CONCLUSIONES}

1. Hemos obtenido harina de camote de los color e s indicados en el trabajo que son :morado, blanco y amarillo

2. El secado se realizó en tres medios: medio ambiente, utilizando la mufla y el secador solar, obteniendo el mejor secado en el medio ambiente a la temperatura de 25 a $32^{\circ} \mathrm{C}$.
3. Experimentalmente se obtuvo en forma artesanal el fideo de baja calidad por los diferentes factores del proceso intermedios.

\section{REFERENCIAS BIBLIOGRÁFICAS}

CASSERES, H. E. (1986). Papa, yuca y camote: cultivo y aprovechamiento. Santiago, Chile, FAO, Oficina Regional para América Latina y el Caribe, p. 40-50.

CONTRERAS R., V. R. (1993). "La batata, importancia y utilización". Revista FONAIAP. (Venezuela), p. 10 11.

CRUZ, L. G. Et al. Evaluación de tres distanciamientos de siembra sobre el rendimiento de cinco variedades de camote (Ipomoea batata) en la Estación Experimental y de Prácticas. Tesis de Ingeniero Agrónomo, Universidad de El Salvador, 80 p.

MISIÓN TÉCNICAAGRÍCOLA DE LA REPUBLICA DE CHINA. Cultivo del camote (Ipomoea batata). Hoja divulgativa, Guatemala. Av. La Universidad 795 - La Molina.

Información proporcionada por el Centro Internacional de la Papa (CIP) Av. La Universidad 795 - La Molina. Teléfono:(51-1)3496017. Fax:(51-1)3175326. 


\section{ANEXOS}

Secador Solar del Departamento de Física

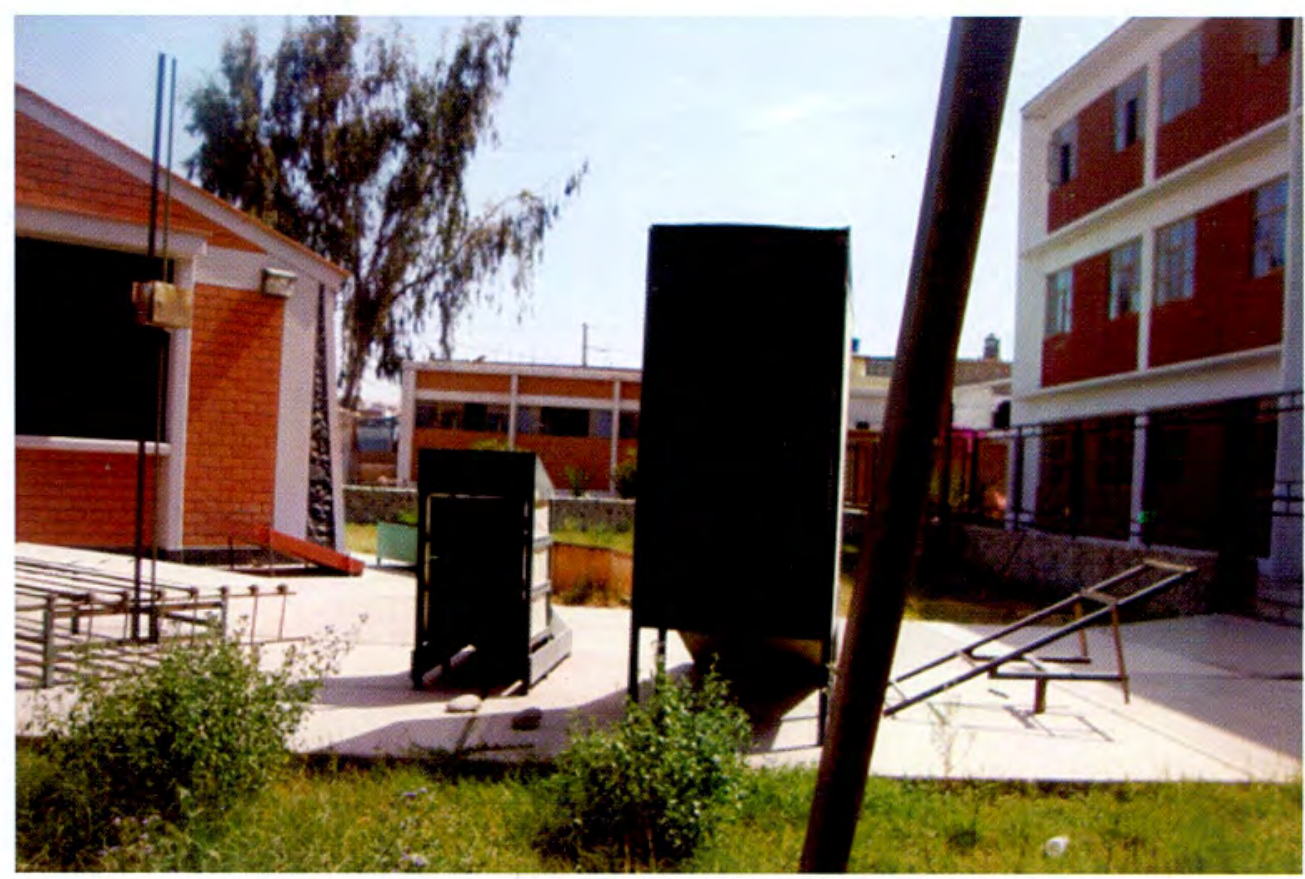

Fideo Artesanal

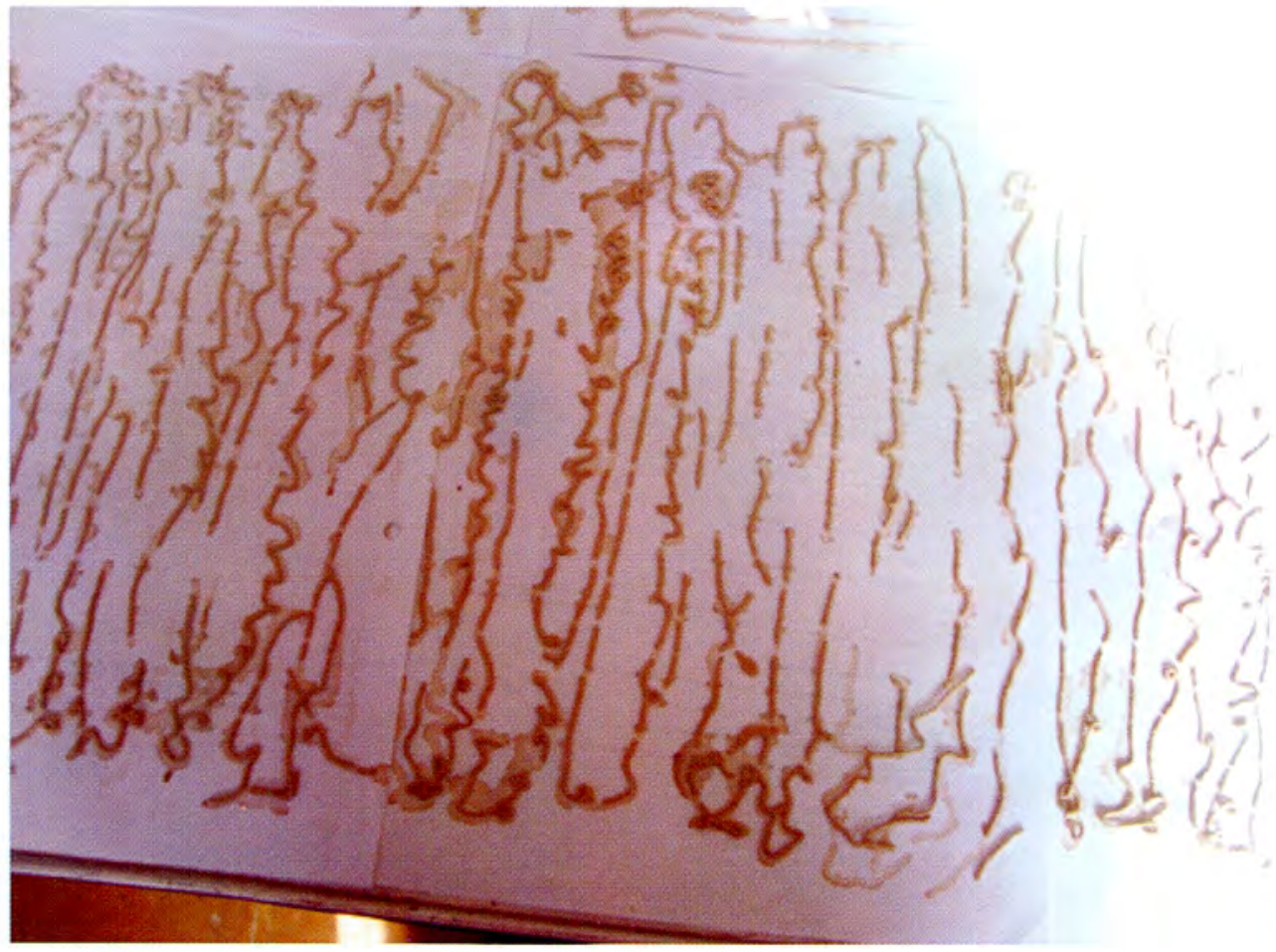

